\title{
Results of combined surgery, mSICS and cyclodialysis, in patients with glaucoma and cataract. Real-life experience, efficacy and safety
}

\section{Resultados de cirugía combinada, mSICS y ciclodiálisis, en pacientes con glaucoma y catarata. Experiencia, eficacia y seguridad}

\author{
Mario R. Papa-Vettorazzi ${ }^{1 *}$, José B. Cruz-Rodríguez², Claudia M. López-Villeda ${ }^{1}$ and \\ Gladys L. Silva-Linares ${ }^{1}$ \\ ${ }^{1}$ Visualiza Clinic, Guatemala, Guatemala; ${ }^{2}$ Texas Tech University Health Sciences Centre, El Paso, Texas, United States of America
}

\begin{abstract}
Objective: To assess the efficacy and safety of combined surgery (manual small incision cataract surgery [mSICS] and cyclodialysis) in eyes with cataracts and advanced glaucoma or uncontrolled ocular hypertension. Method: Retrospective study of 343 consecutive eyes that underwent mSICS and cyclodialysis. All surgeries were performed by experienced surgeons during 2017 and 2018. To evaluate the efficacy and safety of the procedure, we used a control group of 53 consecutive eyes that only underwent cyclodialysis during the same period. In both groups, the change in intraocular pressure (IOP), glaucoma control medications, best-corrected visual acuity (BCVA), complications, and reinterventions were evaluated and compared. Results: The decrease in IOP was greater in the combined surgery group $(p=0.01)$. The need for medications to control glaucoma was lower in the combined surgery group $(p=0.07)$ and, in the same way, BCVA was better in this group ( $p=0.05)$. The frequency of complications was lower in the cyclodialysis group $(p=0.03)$. The frequency of reoperations was lower in the combined surgery group $(p<0.01)$. In both groups, most reoperations were procedures to control IOP. Success and graded success were higher in the combined surgery group $(p<0.01)$. Conclusions: Combined mSICS surgery is effective and relatively safe in eyes with cataracts and advanced glaucoma or with uncontrolled ocular hypertension. It is a low-cost procedure that represents a good alternative in developing countries.
\end{abstract}

Keywords: Cataract. Combined surgery. Cyclodialysis. Glaucoma. mSICS.

\section{Resumen}

Objetivo: Evaluar la seguridad y la eficacia de la cirugía combinada (cirugía manual de incisión pequeña [mSICS] y ciclodiálisis) en ojos con catarata y glaucoma avanzado o hipertensión ocular no controlada. Método: Estudio retrospectivo de 343 ojos consecutivos a los que se realizó mSICS y ciclodiálisis. Todas las cirugías fueron llevadas a cabo por cirujanos experimentados, durante 2017 y 2018. Para evaluar la eficacia y la seguridad del procedimiento se usó un grupo control de 53 ojos consecutivos a los que se realizó únicamente ciclodiálisis durante el mismo periodo. En ambos grupos se evaluaron

Correspondence:

*Mario R. Papa

5ta avda. 11-44, Zona 9

Date of reception: 19-01-2021

C.P. 01009, Guatemala, Guatemala

E-mail: mrpv_papa@hotmail.com
Available online: 01-09-2021 Rev Mex Oftalmol (Eng). 2021;95(5):173-181

www.rmo.com.mx (http://creativecommons.org/licenses/by-nc-nd/4.0/). 
y compararon el cambio en la presión intraocular (PIO), los medicamentos para el control del glaucoma, la agudeza visual mejor corregida (AVMC), las complicaciones y las reintervenciones. Resultados: La disminución de la PIO fue mayor en el grupo de cirugía combinada $(p=0.01)$, la necesidad de medicamentos para el control del glaucoma fue menor en el grupo de cirugía combinada $(p=0.07) y$, del mismo modo, la AVMC fue mejor en este grupo $(p=0.05)$. La frecuencia de complicaciones fue menor en el grupo de ciclodiálisis $(p=0.03)$. La frecuencia de reintervenciones fue menor en el grupo de cirugía combinada $(p<0.01)$. En ambos grupos, la mayoría de reintervenciones fueron procedimientos para controlar la PIO. El éxito y el éxito calificado fueron superiores en el grupo de cirugía combinada $(p<0.01)$. Conclusiones: La cirugía de mSICS y ciclodiálisis es efectiva y relativamente segura en ojos con catarata y glaucoma avanzado o con hipertensión ocular no controlada. Es un procedimiento de bajo costo que representa una buena alternativa en los países en vías de desarrollo.

Palabras clave: Catarata. Ciclodiálisis. Cirugía combinada. Glaucoma. mSICS.

\section{Introduction}

Cataract and glaucoma are the two most common causes of preventable blindness worldwide. ${ }^{1}$ Despite technologic advancements, these conditions still represent a major public health problem, especially in low income countries where access to specialized care and cost of treatment represents an important barrier.

Treatment of cataracts is surgical, whereas therapy for glaucoma may be medical, with laser or surgical, depending on severity. When affected by both conditions, the surgical approach is widely debated, with several advocating to undertake procedures in a specific order and many others favor performing both simultaneously. 2,3,4,5

The gold standard of combined procedures is phacoemulsification + trabeculectomy. However, in low income populations this type of surgery has certain disadvantages mainly derived from its cost and follow-up.

There are some reports concluding that the combination of cataract extraction + cyclodialysis is successful in lowering intraocular pressure (IOP) and reducing the number of postoperative glaucoma medications. ${ }^{6,7}$ This is why manual small incision cataract surgery (mSICS) + cyclodialysis may be a good alternative.

The main purpose of this study was to assess the efficacy and safety of combined mSICS + cyclodialysis compared to cyclodialysis alone. Secondary objectives were to evaluate the short- and long-term changes in IOP, changes in glaucoma medication requirements, changes in BCVA at 3 months, complications and re-interventions.

\section{Methods}

\section{Study design}

We performed a single-center, retrospective cohort study, including 343 consecutive eyes that underwent combined surgery (mSICS + cyclodialysis). Procedures were performed by experienced surgeons using a standard technique during 2017 and 2018. All eyes had a cataract that caused significant visual impairment (visual acuity less than 0.3 logMar) and advanced uncontrolled glaucoma or uncontrolled ocular hypertension (IOP higher than the target considered for each case despite medical or laser therapy [according to clinical evaluation]).

To evaluate the efficacy and safety of the procedure, we used a control group of 53 consecutive eyes that underwent cyclodialysis alone (phakic and pseudophakic eyes) performed by the same group of surgeons during the same period.

In both groups, optic nerve damage assessment and glaucoma classification were made based on clinical evaluation and preoperative IOP (Goldman tonometer).

A manual chart review was performed by one of the investigators and validated by another. Clinical variables evaluated in both groups included age, sex, eye, glaucoma type, excavation (clinical evaluation), date of procedure and last follow-up. Outcome variables included IOP (Goldman tonometer) and number of glaucoma medications at day one, 1 week, 1, 3, 6 and 12 months; postoperative BCVA at 3 months and failure (if present).

An external Institutional Ethics Committee confirmed the exempt status of this work given its retrospective nature and approved the study. This research adhered to the tenets of the Declaration of Helsinki.

Since some visual acuities were expressed in non-numerical terms, they were assigned a rank/value in logMar scale for their analysis (Annex 1).

An $A / B$ scan was performed prior to surgery in all patients with mature cataracts that did not allow fundoscopic evaluation. 


\section{Surgical procedure}

After sedation administered by an anesthesiologist and peribulbar anesthesia application (1:1 mix of $1 \%$ lidocaine, $0.75 \%$ bupivacaine +150 units of hyaluronidase), patients were prepped/draped in the usual way. A lid speculum was placed in the eye, a $6 \mathrm{~mm}$ fornix-based peritomy was performed, followed by light wet field diathermy on episcleral vessels. A 5.5 - $6 \mathrm{~mm}$ scleral incision with a diamond blade or a $15^{\circ}$ scalpel was created starting $1-2 \mathrm{~mm}$ behind the limbus (the location of the peritomy and scleral incision was decided by the surgeon according to preoperative keratometry). This incision was extended with a crescent blade until the limbus was reached advancing it $1-1.5 \mathrm{~mm}$ into clear cornea. A paracentesis with a $3.2 \mathrm{~mm}$, keratome blade was performed. In some cases, surgeons used trypan blue to dye the anterior capsule; then, the anterior chamber was filled with viscoelastic. Subsequently, the entire internal lip of the tunnel incision was opened in a valved fashion with the $3.2 \mathrm{~mm}$ keratome blade. Then, a capsulorhexis using a cystotome was performed, followed by hydrodissection and cataract luxation to the anterior chamber for cataract extraction using an irrigating Vectis. All cortical material was removed using a $21 \mathrm{~g}$ Simcoe cannula. Then, a single-piece polymethyl methacrylate lens was introduced in the capsular bag. After this, a miotic was used and a 2 clock-hour cyclodialysis cleft was performed using the cyclodialysis spatula (location determined by the surgeon).

To create the cyclodialysis, the spatula was introduced through the paracentesis at the opposite quadrant. An initial superficial movement was made to induce a goniotomy. Following this, while maintaining a light upward lift on the sclera, the peripheral cornea was followed with the spatula to reach the scleral spur. Then the tip of the spatula was gently pushed and allowed to pass beyond the scleral spur into the supraciliary space. Once the cyclodialysis was created, the anterior chamber was observed for 1 or 2 minutes to detect any hemorrhage. Finally, the viscoelastic was removed, the paracentesis hydrated, and the main incision verified for wound leakage. The conjunctiva was closed using either diathermy or a 10-0 nylon suture.

In the cyclodialysis alone group, the surgical technique was similar. After sedation, peribulbar anesthesia administration and standard patient preparation. A paracentesis with a $3.2 \mathrm{~mm}$ knife was performed (location decided by the surgeon). A miotic was used. The anterior chamber was filled with viscoelastic. A 2 clockhour cyclodialysis was performed using the same technique described for the combined surgery group (location determined by the surgeon). The anterior chamber was observed for 1 or 2 minutes, then the viscoelastic was removed and the paracentesis hydrated.

All eyes were patched and shielded once the procedure was finished.

\section{Postoperative care}

Patients used combined antibiotic and steroid drops every 1 or 2 hours while awake for seven days, then tapered slowly for 1 month unless inflammation did not resolve. In some cases, pilocarpine $4 \%$ was used 3 times a day to avoid cyclodialysis closure. The follow-up was at day one, then weekly for the first month, and at 3,6 , and 12 months.

\section{Definitions of success, qualified success and failure}

IOP control is often used as a surrogate measure of disease stability in studies about glaucoma surgery. However, there is not a clear and universally accepted definition for success and qualified success. ${ }^{8}$

The strictest target IOP reported on most studies is an IOP $\leq 18 \mathrm{mmHg}^{2,6}$ However, we considered that in patients with advanced glaucoma, the aim should be to obtain lower IOP levels. The Advanced Glaucoma Intervention Study (AGIS) reported that an IOP at which visual field loss stabilizes in an average of $12.3 \mathrm{mmHg}$, also recommending target reductions from baseline of $40 \%$ in severe cases or $30 \%$ in moderate ones. ${ }^{9}$

This is why we performed 2 separate analyses, one with the definition of IOP $<18 \mathrm{mmHg}$ :

- Success: IOP $<18 \mathrm{mmHg}$ without glaucoma medication.

- Qualified success: IOP $<18 \mathrm{mmHg}$ with glaucoma medication.

- Failure: IOP $\geq 18 \mathrm{mmHg}$ or need of subsequent procedures to control IOP.

And the other with the definition suggested by AGIS (used for sensitivity analysis): ${ }^{9}$

- Success: IOP $\leq 12.3 \mathrm{mmHg}$ or a $40 \%$ reduction in severe cases or $30 \%$ reduction in moderate cases, without glaucoma medication.

- Qualified success: IOP $\leq 12.3 \mathrm{mmHg}$ or a $40 \%$ reduction in severe cases or $30 \%$ reduction in moderate cases, with glaucoma medication. 
- Failure: IOP $>12.3 \mathrm{mmHg}$ or less than $40 \%$ reduction in severe cases and less than 30\% reduction in moderate cases, or need of subsequent procedures to control IOP.

\section{Statistical analysis}

We performed descriptive analysis for all the continuous variables. Variables with normal distribution are presented with mean and standard deviation (SD); variables that were not normally distributed are presented with median and interquartile range (IQR). For all the categorical variables, we present frequencies and proportions. According to data distribution, paired t-test or non-parametric Kruskal-Wallis test was used to compare continuous variables. Categorical results were analyzed by chi-square test or Fisher's exact test when the sample was smaller. $P$ values of 0.05 or less were considered statistically significant. Statistical analysis was based on a two-sided significance level. Missing data were handled with the available data method. Kaplan-Meier survival analysis was made for both groups, and Cox regression analysis with the Breslow method for ties was applied to a priori selected clinically relevant variables. Analyses were made using STATA version 14.2 (StataCorp LCC, Tx, USA).

\section{Results \\ Efficacy}

The combined surgery group comprised 343 consecutive eyes, $92 \%$ completed at least 1-month follow-up, $65 \%$ at least a 3 -month follow-up, $51 \%$ a 6 -month follow-up, and 35\% a 12-month follow-up. The cyclodialysis alone group comprised 53 consecutive eyes, $91 \%$ completed at least 1-month follow-up, $68 \%$ at least a 3-month follow-up, 55\% a 6-month follow-up, and 39\% a 12-month follow-up. Mean follow-up was 266 days for the combined surgery group and 231 days for the cyclodialysis alone group. Demographic characteristics are presented in Table 1.

IOP reduction was constant and significant in both groups; however, at the final follow-up, change was greater in the combined surgery group $(p=0.01)$. In an absolute comparison, eyes with combined surgery had a lower IOP (an average of $3.72 \mathrm{mmHg} ; 95 \%$ $\mathrm{Cl}-1.36,-6.07, p<0.01$ ). Mean difference of preoperative and postoperative IOP at the 12-month follow-up was $7.06 \mathrm{mmHg}( \pm 8.5)$ in the combined surgery group and
Table 1. Demographic characteristics, $n=396$

\begin{tabular}{|c|c|c|c|}
\hline Variable & $\begin{array}{c}\text { mSICS + } \\
\text { cyclodialysis }\end{array}$ & Cyclodialysis & p value \\
\hline$n$ & 343 & 53 & \\
\hline Age, mean (SD) & 73.43 (9.79) & 71.69 (14.38) & 0.26 \\
\hline Male & $152(44.3 \%)$ & $29(54.7 \%)$ & 0.16 \\
\hline Right eye & $170(49.6 \%)$ & $28(52.8 \%)$ & 0.66 \\
\hline $\begin{array}{l}\text { Excavation, mean } \\
\text { (SD) }\end{array}$ & $.795(.178)$ & $.858(.148)$ & 0.01 \\
\hline $\begin{array}{l}\text { Type of glaucoma } \\
\text { POAG } \\
\text { CACG } \\
\text { PXG } \\
\text { Other }\end{array}$ & $\begin{array}{l}153(45.4 \%) \\
94(27.9 \%) \\
49(14.5 \%) \\
41(12.2 \%)\end{array}$ & $\begin{array}{c}15(29.4 \%) \\
5(9.8 \%) \\
7(13.7 \%) \\
24(47.1 \%)\end{array}$ & $<0.01$ \\
\hline $\begin{array}{l}\text { Cyclodialysis } \\
\text { localization } \\
\text { SN } \\
\text { IN } \\
\text { ST } \\
\text { IT }\end{array}$ & $\begin{array}{c}205(60.8 \%) \\
65(19.3 \%) \\
28(8.3 \%) \\
39(11.6 \%)\end{array}$ & $\begin{array}{c}27(51.9 \%) \\
7(13.5 \%) \\
14(26.9 \%) \\
4(7.7 \%)\end{array}$ & $<0.01$ \\
\hline $\begin{array}{l}\text { Preoperative } \\
\text { BCVA logMar, } \\
\text { mean (SD) }\end{array}$ & $.965(.619)$ & $.848(.671)$ & 0.20 \\
\hline $\begin{array}{l}\text { Preoperative } \\
\text { medication, mean } \\
\text { (SD) }\end{array}$ & $1.57(1.40)$ & $2.37(1.27)$ & $<0.01$ \\
\hline $\begin{array}{l}\text { Preoperative IOP, } \\
\text { mean (SD) }\end{array}$ & 20.14 (7.79) & 23.15 (7.05) & 0.01 \\
\hline $\begin{array}{l}\text { Postoperative } \\
\text { BCVA logMar, } \\
\text { mean (SD) }\end{array}$ & $.445(.461)$ & $.622(.706)$ & 0.05 \\
\hline $\begin{array}{l}\text { nSICS: manual Small Inc } \\
\text { OAG: primary open-angl } \\
\text { XG: pseudoexfoliation-a } \\
\text { teroid-induced glaucom } \\
\text { SN: superior-nasal, IN: in } \\
\text { CCVA: best-corrected vis }\end{array}$ & $\begin{array}{l}\text { Cataract Surge } \\
\text { ucoma, CACG: } \\
\text { ated glaucoma, } \\
\text { nbined mechan } \\
\text {-nasal, ST: supe } \\
\text { uity, IOP: intrac }\end{array}$ & $\begin{array}{l}\text { : standard devia } \\
\text { ic angle-closure } \\
\text { rs: ocular hypert } \\
\text { laucoma, pigmer } \\
\text { emporal, IT: infe } \\
\text { r pressure. }\end{array}$ & $\begin{array}{l}\text { coma, } \\
\text { on, } \\
\text { glaucoma. } \\
\text { emporal. }\end{array}$ \\
\hline
\end{tabular}

$5.33 \mathrm{mmHg}( \pm 11.02)$ in the cyclodialysis alone group. Figure 1.

Although the combined surgery group needed less medications preoperatively, at the last follow-up, the number of medications required was 0.78 lower compared to the cyclodialysis alone group $(p<0.01)$. Mean decrease in glaucoma medication requirements at the 12-month follow-up was $0.576( \pm 1.33)$ in the combined surgery group and $0.476( \pm 1.96)$ in the cyclodialysis alone group. Figure 2.

Applying the $<18 \mathrm{mmHg}$ definition, the combined surgery group did not reach the median time to failure at the end of follow-up; it reached the $75^{\text {th }}$ percentile at 620 days (1.7 years). The median time to failure for the cyclodialysis 


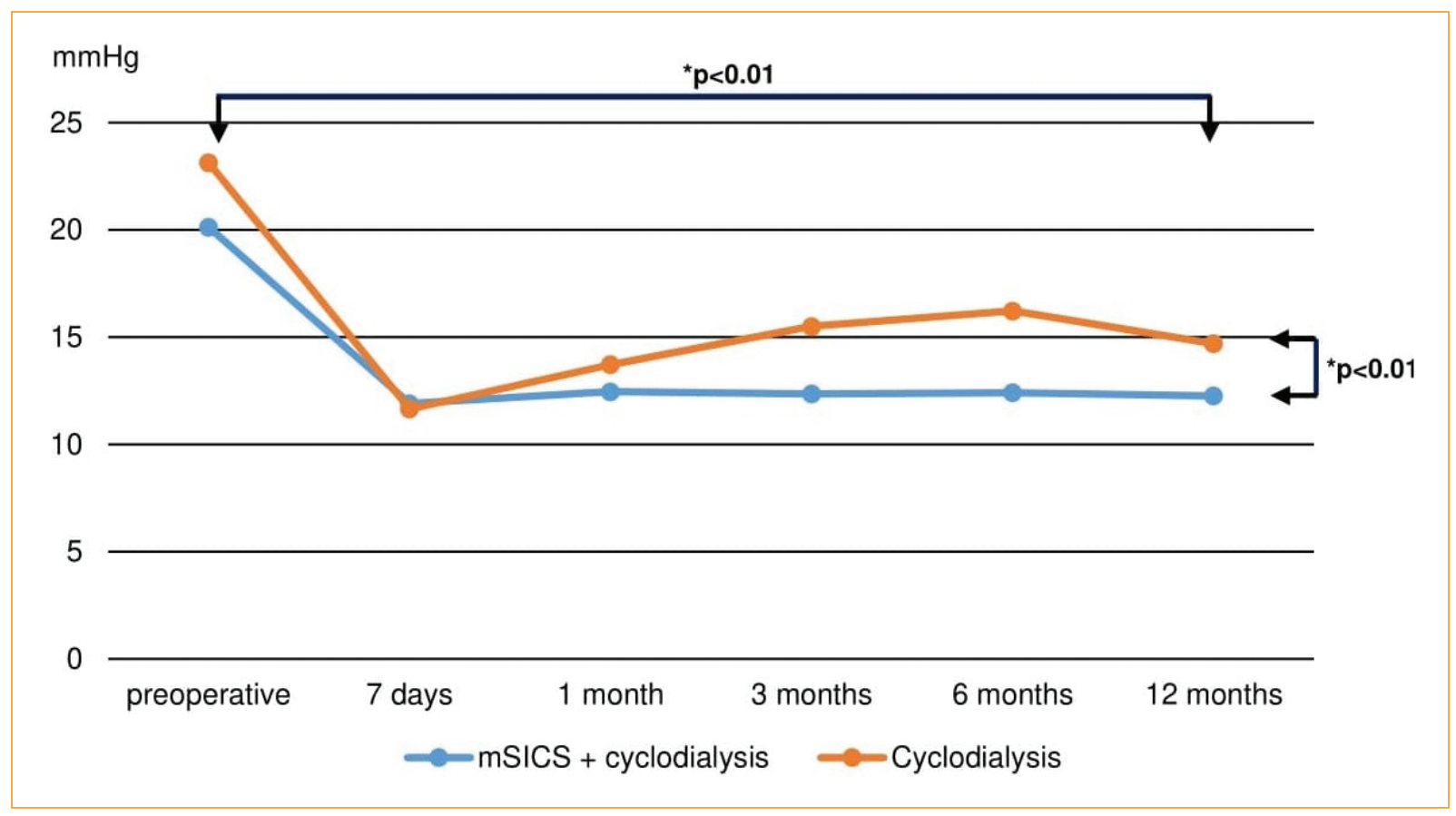

Figure 1. Line graph representing a change in IOP over time and comparison of both study groups. Combined surgery group $\mathrm{N}=343$, cyclodialysis alone group $\mathrm{N}=53$. $\mathrm{P}$-values represent a paired t-test for each individual group comparing preoperative IOP with IOP at the 12-month assessment and t-test for comparing both groups.

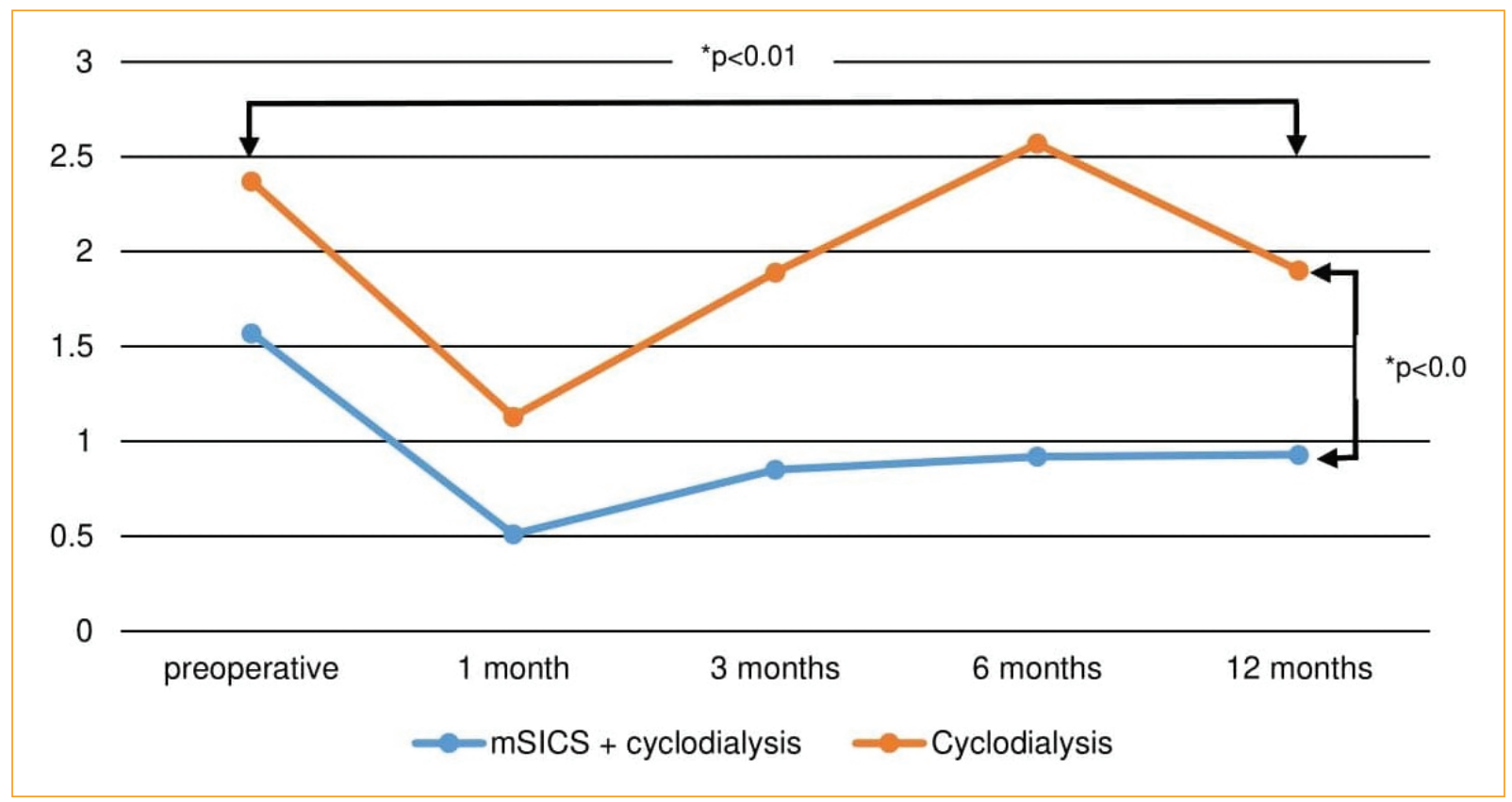

Figure 2. Line graph showing a postoperative reduction in glaucoma medication requirements and comparison between both study groups: combined surgery group $\mathrm{N}=343$ and, cyclodialysis alone group $\mathrm{N}=53$. $\mathrm{P}$-values represent a paired t-test for each individual group comparing preoperative medication requirements with medication requirements at the 12-month assessment and t-test for comparing both groups. 


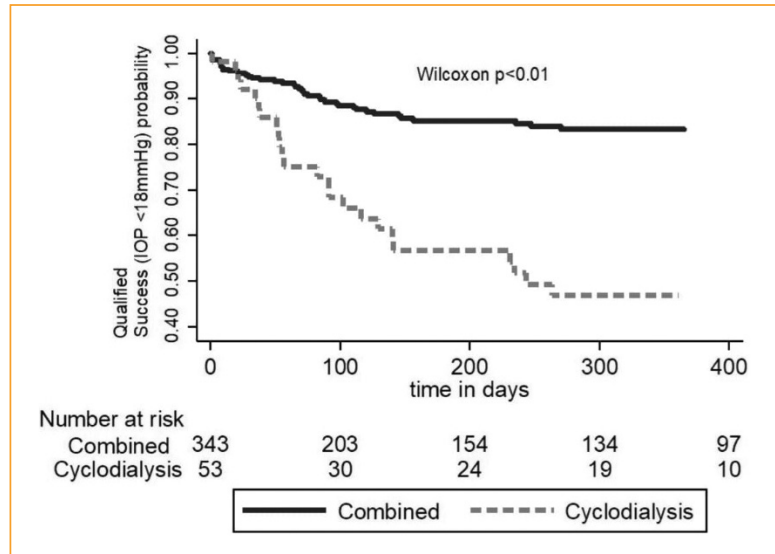

Figure 3. Kaplan-Meier survival curve showing the cumulative probability of no treatment failure over time for both groups (IOP $<18 \mathrm{mmHg}$ ). Combined surgery group $\mathrm{N}=343$, cyclodialysis alone group $\mathrm{N}=53$. The difference between groups is represented by the Wilcoxon log-rank.

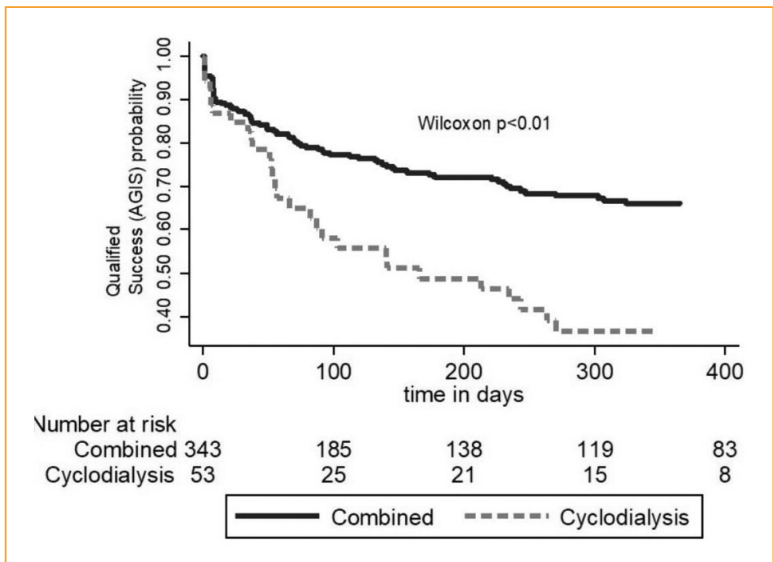

Figure 4. Kaplan-Meier survival curve showing the cumulative probability of no treatment failure over time for both groups (IOP $\leq 12.3 \mathrm{mmHg}$ or a $40 \%$ reduction in severe cases or $30 \%$ reduction in moderate cases). Combined surgery group $\mathrm{N}=343$, cyclodialysis alone group $\mathrm{N}=53$. The difference between groups is represented by the Wilcoxon log-rank.

alone group was 243 days (8 months). Qualified success rates at the end of the first year were $83.4 \%$ for the combined surgery group and $46.8 \%$ for the cyclodialysis alone group (Wilcoxon log-rank $p<0.01$ ). Figure 3.

Applying the AGIS definition, the cyclodialysis alone group had a higher failure rate at every time point, with a median time to failure of 166 days (5.5 months), compared to a median time to failure of 747 days ( 2.05 years) in the combined surgery group. Qualified success rates
Table 2. Success and qualified success rates over the entire follow-up

\begin{tabular}{|c|c|c|c|}
\hline & $\underset{\text { cyclodialysis }}{\text { mSICS + }}$ & Cyclodialysis & $\mathrm{p}$ value \\
\hline $\begin{array}{l}\text { Success (IOP } \\
<18 \mathrm{mmHg} \text { ) }\end{array}$ & $197(57.4 \%)$ & $15(28.3 \%)$ & $<0.01$ \\
\hline $\begin{array}{l}\text { Qualified success } \\
\text { (IOP }<18 \mathrm{mmHg} \text { ) }\end{array}$ & $289(84.3 \%)$ & $28(52.8 \%)$ & $<0.01$ \\
\hline Success AGIS & $166(48.4 \%)$ & $14(26.4 \%)$ & $<0.01$ \\
\hline $\begin{array}{l}\text { Qualified success } \\
\text { AGIS }\end{array}$ & $232(67.6 \%)$ & $24(45.3 \%)$ & $<0.01$ \\
\hline
\end{tabular}

mSICS: manual Small Incision Cataract Surgery. AGIS: Advanced Glaucoma Intervention Study.

Table 3. Multivariable Cox proportional Hazard Model

\begin{tabular}{|c|c|c|c|c|}
\hline & $\begin{array}{c}\text { IOP } \\
<18 \mathrm{mmHg}\end{array}$ & p value & $\begin{array}{c}\text { AGIS } \\
\text { definition }\end{array}$ & $p$ value \\
\hline $\begin{array}{l}\text { Combined } \\
\text { surgery } \\
\text { (reference: } \\
\text { cyclodialysis } \\
\text { alone) }\end{array}$ & 0.33 & $<0.01$ & 0.50 & $<0.01$ \\
\hline $\begin{array}{l}\text { Diagnosis } \\
\text { (Reference } \\
\text { POAG) }\end{array}$ & - & - & - & - \\
\hline CACG & 1.09 & 0.79 & 1.00 & 0.98 \\
\hline PXG & 1.92 & 0.05 & 1.65 & 0.05 \\
\hline Others & 1.15 & 0.66 & 1.21 & 0.43 \\
\hline $\begin{array}{l}\text { Location of } \\
\text { cyclodialysis } \\
\text { (reference: SN) }\end{array}$ & - & - & - & - \\
\hline IN & 0.73 & 0.35 & 0.60 & 0.05 \\
\hline ST & 0.65 & 0.30 & 0.64 & 0.15 \\
\hline IT & 1.16 & 0.71 & 0.93 & 0.79 \\
\hline $\begin{array}{l}\text { Baseline IOP } \\
\text { with treatment }\end{array}$ & 1.06 & $<0.01$ & 1.00 & 0.74 \\
\hline
\end{tabular}

AGIS: Advanced Glaucoma Intervention Study. POAG: primary open-angle glaucoma, CACG: chronic angle-closure glaucoma, PXG: pseudoexfoliationassociated glaucoma, Others: ocular hypertension, steroid-induced glaucoma, combined mechanism glaucoma, pigmentary glaucoma. SN: superior-nasal, IN: inferior-nasal, ST: superior-temporal, IT: inferior-temporal.

at the end of the first year were $66.1 \%$ for the combined surgery group and $36.7 \%$ for the cyclodialysis alone group. (Wilcoxon log-rank $p<0.01$ ). Figure 4.

Success and qualified success rates applying both definitions were significantly better in the combined surgery group, even when the stricter definition was applied. Table 2.

Cox regression was applied, aiming to predict the events. In raw data analysis, the risk of developing an event was $49 \%$ lower (HR 0.51, p=0.002, 95\% Cl 
Table 4. Complications and re-interventions

\begin{tabular}{|c|c|c|c|}
\hline Variable & $\begin{array}{c}\text { mSICS + } \\
\text { cyclodialysis }\end{array}$ & Cyclodialysis & $p$ value \\
\hline $\begin{array}{l}\text { Complications } \\
\text { PCR + AVT } \\
\text { Hyphema (that } \\
\text { required } \\
\text { treatment) } \\
\text { Hypotony } \\
\text { Others }\end{array}$ & $\begin{array}{l}21(6.1 \%) \\
12(3.5 \%) \\
2(0.6 \%) \\
1(0.3 \%)\end{array}$ & $\begin{array}{l}0(0.0 \%) \\
0(0.0 \%) \\
0(0.0 \%) \\
0(0.0 \%)\end{array}$ & 0.03 \\
\hline $\begin{array}{l}\text { Re-interventions } \\
\text { Procedures to } \\
\text { control IOP } \\
\text { Anterior } \\
\text { chamber } \\
\text { washout } \\
\text { Others }\end{array}$ & $\begin{array}{l}25(7.2 \%) \\
15(4.3 \%) \\
4(1.1 \%)\end{array}$ & $\begin{array}{c}13(24.5 \%) \\
0(0.0 \%) \\
0(0.0 \%)\end{array}$ & $<0.01$ \\
\hline
\end{tabular}

mSICS: manual Small Incision Cataract Surgery. PCR + AVT: posterior capsule rupture + anterior vitrectomy. IOP: intraocular pressure.

0.34-0.84) in patients that underwent combined surgery compared to those that underwent cyclodialysis alone.

After adjusting for a priori selected variables given their clinical impact on the outcome (diagnosis, cyclodialysis location and baseline IOP), the risk of developing an event was $67 \%$ lower (HR 0.33, p<0.01, 95\% Cl $0.20-0.57$ ) in patients assigned to combined surgery compared to those assigned to cyclodialysis alone.

For every $1 \mathrm{mmHg}$ increase in baseline IOP, the risk of having a failure increased by $6 \%$ (HR 1.06, $p<0.01$, $95 \% \mathrm{Cl} 1.03-1.09)$. In this same multivariable analysis, there was no association between the diagnosis or location of the cyclodialysis with the development of failure. These findings were consistent when applying the stricter AGIS definition. Table 3.

\section{Safety}

Complications occurred in $10.5 \%$ of the combined surgery group compared to $0 \%$ in the cyclodialysis alone group $(p=0.03)$. As displayed in Table 4 , in the combined surgery group, most of the complications were related to cataract surgery (posterior capsule rupture (PCR) 6.1\%). Re-intervention proportion was higher in the cyclodialysis alone group $(p<0.01)$.

\section{Discussion}

Several outcome studies including randomized trials support that mSICS is almost as effective, equally safe and faster to perform than phacoemulsification, but the cost of mSICS is substantially lower (US\$ $15.0-15.74$ vs US\$ 42.0 - 70.0). ${ }^{10,11}$ For this reason, mSICS seems like the best option in developing countries.

In our cohort, combined mSICS + cyclodialysis performed better than cyclodialysis alone in terms of efficacy. BCVA improved in both groups. The combined surgery group achieved a better BCVA at 3 months $(p=0.05)$. In our cohort of eyes with combined surgery, BCVA remained unchanged or improved in $90 \%$ of the cases. This is similar to a combined surgery study published by Stark $(93 \% \text { of the eyes improved BCVA })^{5}$. Furthermore, $61 \%$ of eyes in our combined surgery group achieved a BCVA of 0.3 logMar or better, comparable to the combined surgery reports of Mamalis (63\%), Simmons (64\%) and Murchinson (65\%), but lower than the reports of Ruderman (72\%) and Stark $(81 \%))^{3,4,5}$

The effect on IOP reduction was sustained and stable in both groups, with significantly lower values at 12 months for both types of surgery. However, the difference between groups was significant. At the last follow-up, eyes with combined surgery achieved lower IOP levels $(p<0.01)$. On average, the percentage of IOP reduction in the combined surgery group was $29 \%$, this is similar to the reports of Mamalis $30.8 \%$ and Ruder$\operatorname{man} 34 \% .^{3,4}$

Both groups showed a significant reduction in glaucoma medication requirements $(p<0.01)$. Even though eyes in the combined surgery group used less preoperative medications, at the final follow-up, the reduction in glaucoma medication requirements was significantly higher in eyes with combined surgery $(p<0.01)$. The mean reduction of glaucoma medication requirements in our combined surgery group was $0.576( \pm 1.33)$; this is lower than the 1.44 reported by Mamalis. $^{4}$

When comparing the success and qualified success rates between groups, eyes in the combined surgery group had better outcomes applying both definitions (IOP $<18 \mathrm{mmHg}$ and AGIS) $(p<0.05)$. A potential reason for this is that the cyclodialysis cleft is more likely to close in phakic eyes rather than in pseudophakic ones. In fact, in our series, most failures in the cyclodialysis alone group occurred in phakic eyes. Although the reason is uncertain, we hypothesize that cataract extraction may allow the iris and ciliary body to fall posteriorly, thereby placing tension on the scleral spur, and preventing the closure of the cyclodialysis cleft. ${ }^{3}$

In combined surgery (phacoemulsification + trabeculectomy) the reports on success rates range from 67 to $78 \%$, and qualified success rates range from 74 to $85 \%$ (IOP less than $21 \mathrm{mmHg}$ ). $4,5,12$ 
There are few reports of combined cataract surgery + cyclodialysis. In these reports, success rates range from 60 to $83 \%$, and qualified success rates range from 72 to $90 \%$ (IOP less than $18 \mathrm{mmHg}$ or $20 \mathrm{mmHg}$ ). ${ }^{6,7}$

In our series, qualified success for the combined surgery-group was $84.3 \%$ (IOP $<18 \mathrm{mmHg}$ ) and $67.6 \%$ (AGIS). When we compare our results with the literature they are similar, even when we apply the AGIS definition.

Mean survival time was significantly better in the combined surgery group $(p<0.01)$. Survival analysis showed that when the $<18 \mathrm{mmHg}$ definition was applied, eyes in the combined surgery group did not reach the median time to failure at the end of follow-up. When the AGIS definition was applied, the median time to failure was 747 days (2.05 years). This is similar to the results of a combined surgery study published by Rowan, in which the mean survival time was 34.6 months (2.8 years); however, failure in this study was defined as an IOP $>21 \mathrm{mmHg}^{7}$

In terms of safety, the cyclodialysis alone group showed better results $(p=0.03)$. However, most complications in the combined surgery group were related to cataract surgery, occurring mostly in eyes with hypermature cataracts, pseudoexfoliation-associated glaucoma (PXG) and known zonular weakness. PCR rate in the combined surgery group was $6.1 \%$, this is higher than the $2.8 \%$ PCR rate reported by Shields and Simmons in a combined surgery study; however, they excluded eyes with known zonular weakness from their analysis. ${ }^{6}$ Excluding eyes with zonular weakness, the PCR rate in our cohort decreases to $2.9 \%$. The overall complication rate in our combined surgery group was $10.5 \%$, this is lower compared to complication rates from other combined surgery studies $(21-36 \%))^{3,4,5,6,7}$

In this study, the re-intervention rate was higher in the cyclodialysis alone group $(p<0.01)$. Most re-interventions in both groups were procedures to control IOP. It is possible that the higher rate of procedures to control IOP in the cyclodialysis alone group were, as we mentioned before, because the cyclodialysis cleft is more likely to close in phakic eyes than in pseudophakic ones. When excluding phakic eyes from the analysis, the re-intervention rate is similar in both groups.

In the combined surgery group, the overall re-intervention rate was $12.6 \%$, similar to the $13.8 \%$ reported by Shingleton in a combined surgery study. Accordingly, most re-interventions were procedures to control IOP. ${ }^{13}$

In our combined surgery group, $2.9 \%$ of the eyes required an anterior chamber washout as a treatment for hyphema. Other combined surgery studies report a proportion of postoperative hyphema that ranges from $4-28 \% .3,4,6,7$

This study is not free of limitations. Sample size and restricted follow-up limited the statistical power of the results. As we collected data from a single-center and since missing data was handled with the available data method, some selection bias could be present (if the missing pattern was not completely random, however, missing data was less than 3\%). Data was analyzed for changes in each intervened eye over time, and although paired analyses were used, unmeasured confounding could exist. Another limitation of our study is that optic nerve damage assessment and glaucoma classification were made based on clinical evaluation and preoperative IOP (instead of visual field damage or OCT). Finally, it is important to mention that patients with underlying ocular disorders different than glaucoma were included in the analysis; this influenced postoperative BCVA results. We believe that further prospective studies, including bigger sample size and randomized blind interventions should be performed to allow adjustment for other confounders and draw causal conclusions.

In summary, our results provide real-life experience data to help surgeons decide whether to perform a combined surgery rather than performing a two-step approach. Our study showed that combined mSICS + cyclodialysis is an effective and reasonably safe procedure comparable to the gold standard in terms of success rates, IOP control, reduction in glaucoma medication requirements, BCVA, and complications. Considering these findings, mSICS + cyclodialysis can be particularly useful in developing countries.

\section{Funding}

This research did not receive any specific grant from funding agencies in the public, commercial, or not-forprofit sectors.

\section{Conflicts of interests}

No conflicting relationship exists for any author.

\section{Ethical disclosures}

Protection of human and animal subjects. The authors declare that no experiments were performed on humans or animals for this study. 
Confidentiality of data. The authors declare that they have followed the protocols of their work center on the publication of patient data.

Right to privacy and informed consent. The authors declare that no patient data appear in this article.

\section{Annex}

Annex 1. Visual acuity, assigned values for statistical analysis.

\begin{tabular}{|l|l|}
\hline Snellen & LogMar \\
\hline $20 / 20$ & 0.00 \\
\hline $20 / 25$ & 0.09 \\
$20 / 30$ & 0.17 \\
$20 / 40$ & 0.30 \\
$20 / 50$ & 0.39 \\
$20 / 60$ & 0.47 \\
$20 / 70$ & 0.54 \\
$20 / 80$ & 0.60 \\
$20 / 100$ & 0.69 \\
$20 / 140$ & 0.84 \\
$20 / 200$ & 1.00 \\
\hline $20 / 400$ & 1.30 \\
CD & 1.80 \\
\hline MM & 1.90 \\
\hline L & 2.00 \\
\hline NPL & 2.50 \\
\hline
\end{tabular}

CD: counting fingers

MM: hand movement

$\mathrm{PL}$ : light perception

NPL: no light perception.

\section{References}

1. Bourne RRA, Stevens GA, White RA, et al. (2013) Causes of vision loss worldwide, 1990-2010: A systematic analysis. The Lancet Global Health. 1(6), 339-349. https://doi.org/10.1016/S2214-109X(13)70113-X

2. Mathew RG, Parvizi S, Murdoch IE. (2019) Success of trabeculectomy surgery in relation to cataract surgery: 5-year outcomes. British Journal of Ophthalmology. 103(10), 1395-1400. https://doi.org/10.1136/bjophthalmol-2018-312972

3. Ruderman JM, Fundingsland B, Meyer MA. (1996) Combined phacoemulsification and trabeculectomy with mitomycin-C. Journal of Cataract and Refractive Surgery. 22, 1085-1090.

4. Mamalis N, Lohner S, Rand AN, et al. (1996) Combined phacoemulsification, intraocular lens implantation, and trabeculectomy. Journal of Cataract and Refractive Surgery. 22(4), 467-473. https://doi.org/10.1016/ S0886-3350(96)80044-7

5. Stark WJ, Goyal RK, Awad O, et al. (2006) The safety and efficacy of combined phacoemulsification and trabeculectomy with releasable sutures. British Journal of Ophthalmology. 90(2), 146-149. https://doi. org/10.1136/bjo.2005.078212

6. Shields MB, Simmons RJ.(1976) Combined Cyclodialysis and Cataract Extraction. Ophthalmic Surgery. 7(2), 62-73.

7. Rowan PJ. (1998) Combined Cyclodialysis and Cataract Surgery. Ophthalmic Surgery and Lasers. 29(12), 962-968.

8. Rotchford AP, King AJ. (2010) Moving the Goal Posts. Definitions of Success after Glaucoma Surgery and Their Effect on Reported Outcome. Ophthalmology. 117(1), 18-23.e3. https://doi.org/10.1016/j.ophtha.2009.06.014

9. Van Veldhuisen PC, Ederer F, Gaasterland DE, et al. (2000) The Advanced Glaucoma Intervention Study (AGIS): The relationship between control of intraocular pressure and visual field deterioration. American Journal of Ophthalmology. 130(4), 429-440. https://doi.org/10.1016/ S0002-9394(00)00538-9

10. Goate M. Parikshit, M. D. (2007). Why do phacoemulsification? Manual small-incision cataract surgery is almost as effective, but less expensive. Ophthalmology, 965-968.

11. Ruit S, t. G. (2007). A prospective randomized clinical trial of phacoemulsification vs manual sutureless small-incision cataract surgery in Nepal. Am J Ophthalmology, 32-38.

12. Longstaff S, Wormald RPL, Mazover A, et al. (1990) Glaucoma Triple Procedures: Efficacy of Intraocular Pressure Control and Visual Outcome. Ophthalmic Surgery. 21(11), 786-793.

13. Shingleton BJ, Wooler $\mathrm{KB}$, Bourne $\mathrm{Cl}$, et al. (2011) Combined cataract and trabeculectomy surgery in eyes with pseudoexfoliation glaucoma. Journal of Cataract and Refractive Surgery. 37(11), 1961-1970. https:/ doi.org/10.1016/j.jcrs.2011.05.036 